\title{
Hemodynamic monitoring by USCOM during rapid sequence intubation (RSI) with Etomidate/Fentanyl or Ketamine/Midazolam
}

\author{
Sandra Geiger ${ }^{1}$, Hans Joachim Stemmler ${ }^{*}$, Nina Strecker ${ }^{1}$, Johanna Tischer ${ }^{1}$, Alessandro Pastore ${ }^{1}$, Andreas Hausmann ${ }^{1}$ and Sophia Horster ${ }^{2}$ \\ Correspondence: Joachim.Stemmler@med.uni-muenchen.de \\ ${ }^{1}$ Medical Dept. III and ${ }^{2}$ Medical Dept. II, Intensive Care Unit F 2 b/c, Ludwig-Maximilians University of Munich, \\ Campus Großhadern, Munich, Germany.
}

\begin{abstract}
Background: Critically ill and septic patients often require emergency orotracheal intubation. Etomidate is associated with a reversible adrenal insufficiency which potentially increases the in-hospital mortality, particularly in patients with sepsis. Moreover; standard anesthetization might severely aggravate shock symptoms during rapid sequence induction (RSI). Ketamine with its known stabilizing effects on hemodynamics might be a reasonable alternative, particularly in septic patients.
\end{abstract}

Methods: This non-randomised, observational pilot study focuses on the influence of ketamine-based $(\mathrm{K})$ vs an etomidate-based (E) anesthetization on hemodynamic parameters during RSI. Forty pts were assigned alternately to etomidate/fentanyl $(n=20)$, or ketamine/midazolam $(n=20)$ while monitoring with invasive blood pressure (IBP) and ultrasound cardiac output monitor (USCOM) measurements during RSI. The levels of vasopressors required prior to, during and after RSI were recorded.

Results: Fourty patients (median SAPS II score at ICU admission: 54 K, 50 E; median age: 59 yrs K, 56 yrs E) who needed sedation for emergency intubation were sedated either with etomidate/fentanyl or ketamine/midazolam. Noradrenalin demand and mean arterial pressure (MAP) prior to RSI were comparable (E: mean NA dose $0.2 \mathrm{mg} / \mathrm{h}$, MAP $88 \mathrm{mmHg}$; K: mean NA dose $0.45 \mathrm{mg} / \mathrm{h}$, MAP $75 \mathrm{mmHg}$ ) between the two groups. Moreover, mean MAP levels post RSI were 75 (E) and $76(\mathrm{~K}) \mathrm{mmHg}$, respectively. The mean peak level of noradrenalin demand during RSI, though, was considerably higher within the etomidate group compared to the ketamine group (E $7.6 \mathrm{mg} / \mathrm{h}$ vs K $1.06 \mathrm{mg} / \mathrm{h}, \mathrm{p} 0.01$ ). Stroke volume index (SVI) and cardiac index (CI) increased during RSI (+3.8\%/+3.0\%) within the ketamine group, while SVI and CI decreased during RSI $(-8.5 \% /-3.5 \%)$ within the etomidate group.

Conclusion: USCOM is an easily applicable and quick tool for the hemodynamic monitoring of critical ill patients. Moreover, this pilot study shows that RSI with ketamine/midazolam is a safe and valuable alternative to etomidate/ fentanyl in patients who primarily require vasopressors.

Key words: Hemodynamic monitoring, USCOM, intubation, RSI, ketamine, etomidate

\section{Background}

Critically ill patients often require emergency orotracheal intubation. The concomitant use of a sedative and a paralytic agent is common for rapid sequence induction (RSI).

Etomidate is one of the most often used hypnotic agents with outstanding intubation conditions and hemodynamic tolerance even in patients with shock. However, it can cause a reversible adrenal insufficiency by the inhibition 11 b-hydroxylase $[1,2]$. An association between the use of etomidate and an increased morbidity of critically ill and septic patients due to adrenal insufficiency has been suggested in several studies [3-6].
Standard anesthetization might severely aggravate shock symptoms during RSI. Ketamine with its known stabilizing effects on hemodynamics might be a reasonable alternative, particularly in septic patients. A recently published randomized trial has shown that ketamine is a safe and valuable alternative to etomidate for endotracheal intubation in critically ill patients [7]. Jabre et al., found that the percentage of patients with adrenal insufficiency was significantly higher in the etomidate group than in the ketamine group [7].However, 28-day mortality did not differ significantly.

Thermodilution cardiac output measurements have been

(C) 2012 Stemmler et al; licensee Herbert Publications Ltd. This is an Open access Article distributed under the terms of Creative Commons Attribution License (http://creativecommons.org/licenses/by/3.0). This permits unrestricted use, distribution, and reproduction in any medium, provided the original work is properly cited. 
routinely performed as part of intensive care practice since the introduction of the balloon-directed thermistor-tipped pulmonary artery catheter in the 1970s [8-10]. Introduced by Swan and Ganz the pulmonary artery catheter (PAC) became the gold standard for more than two decades $[8,9]$. However, arrhythmia, infection and possible pulmonary artery disruption have always been concerns related to the use of a PAC and led to a growing interest in the development of non-invasive hemodynamic monitoring devices [11-13]. One less invasive thermodilution-based technique consists of the pulse induced cardiac output device (PiCCO) but exclusively ultrasound-based devices as the USCOM monitor are entirely non-invasive methods for measuring $\mathrm{CO}$ [14-20]. Beside accuracy and the method related risks another crucial criterion consists of the time required for the determination of $\mathrm{CO}$ [21]. USCOM is a feasible, continuous-wave Doppler-based method which non-invasively measures $\mathrm{CO}$ in a fast and economical way [22].

The present non-randomised, observational pilot study study aimed at the influence of ketamine-based (ketamine/ midazolam) vs an etomidate-based (etomidate/fentanyl) anesthetization on hemodynamic parameters during RSI.

\section{Patients and methods}

\section{Study setting and patients}

Fourty patients, who needed sedation for emergency intubation, were included in this non-randomized, prospective observational study. Patients were recruited from June 2010 until November 2010, on a ten-bed, non-cardiological medical ICU at the university hospital, Munich. The study protocol was approved by the institutional ethics committee. Informed consent was waived at inclusion because patients needed urgent intubation. Consent for data processing was given by patients, whenever possible, or by relatives and/or legally authorised representatives.

Patients who were 18 years or older who needed sedation for emergency intubation were prospectively enrolled in the study. Exclusion criteria were cardiac arrest and resuscitation, contraindications to one of the agents used for analgo-sedation, known pregnancy.

Patients were alternately assigned to anaesthetization either with etomidate /fentanyl or ketamine/midazolam for intubation. Patients within the etomidate group received first fentanyl $(20-40 \mu \mathrm{g})$ followed by etomidate $(0.2 \mathrm{mg} /$ $\mathrm{kg})$. Those who were assigned to ketamine received 2-4 $\mathrm{mg}$ midazolam, followed by ketamine $(1.5 \mathrm{mg} / \mathrm{kg})$ and immediately thereafter, rocuronium as intravenous bolus $(1 \mathrm{mg} / \mathrm{kg}$ ). After confirmation of intubation and tube placement (using capnometry), continous sedation was initiated by the use of midazolam or propofol combined with sufentanil.

All patients were continuously measured for hemodynamics including heart rate, ECG, oxygen saturation, invasive blood pressure (IBP) and, intermittently, left-sided USCOM (aortal access) immediately prior to, during and after intubation (SVI, stroke volume index; $\mathrm{Cl}$, cardiac index; SVRI, systemic vascular resistance index). To exclude inter-individual observer variability, measurements by USCOM were undertaken by the same investigator. The investigator who performed all the USCOM measurements was not blinded to the induction drugs given. All USCOM measurements were performed immediately prior to induction (first USCOM) and immediately post-intubation (second USCOM) but, throughout the cohort, prior to the start of the post-intubation sedation regime (with propofol or midalolam plus sufentanil). Moreover, all second USCOM measurements were undertaken during a similar ventilation setting (fiO 2 1.0, PEEP 8 mbar).

The maximum use of norepinephrine during the procedure was recorded.

\section{USCOM}

The USCOM-device (USCOM Ltd, Sydney, Australia) is a noninvasive bedside method to evaluate cardiac output basing on continuous-wave Doppler ultrasound. After starting the USCOM device, the left-sided transaortic $\left(\mathrm{CO}_{\text {US-A }}\right)$ or right-sided transpulmonary access has to be choosen before the patients data like height, weight and gender are typed in. The flow profile is obtained by commonly using a $2.2 \mathrm{MHz}$ transducer placed on the chest in either the left parasternal position to measure transpulmonary blood flow (right-sided access, $3^{\text {rd }}$ to $5^{\text {th }}$ parasternal intercostal space) or the suprasternal position to measure transaortic blood flow (left-sided access, suprasternal notch). The operator registries a Doppler flow curve with maximal blood flow which is characterized by a sharp, well-defined waveform with the clearest audible sound. The flow profile is displayed as a time velocity curve at the monitor (VTI=velocity time integral). Once the optimal flow profile is obtained, the trace is frozen. The USCOM device calculates $\mathrm{CO}$ by the product of stroke volume (SV) and heart rate $(\mathrm{HR})$ where the SV is the product of the velocity time integral (VTI) and the cross-sectional area of the choosen valve (CSA). The valve cross-sectional area is given by the USCOM internal algorithm based on the formerly typed in patients data (height and gender).

\section{Statistical analysis}

Statistical analysis was performed with SPSS (SPSS for Windows, Version 15.0, SPSS Institute, Chicago, III., USA) using the t-test. A difference of $p<0.05$ between the variables was considered as statistically significant.

\section{Results}

\section{Baseline characteristics}

All patients ( 23 male, 17 female) suffered from septic complications and required primarily catecholamines. The median age was 59 years ( $K$ ) and 56 years (E) and the median SAPS Score was 54 (K) and 50 (E) points at ICU admission.

The majorities of the patients suffered from hemato-oncological or hepatological disease. Six patients had received 
prior chemotherapy for solid tumors, and 10 patients suffered from other diseases. Intubation was indicated mainly for respiratory failure and/or sepsis ( $n=33,82.5 \%$ ).

Detailed patients characteristics are given in Table 1.

\section{Blood pressure, heart rate and catecholamine use during RSI}

Prior to RSI, patients within both groups (K ketamine, E etomidate) were comparable regarding heart rate (HR, K 104 vs $\mathrm{E}$ 107 bpm; $p$ 0.67) and mean arterial pressure (MAP, K 75 vs E 88 $\mathrm{mmHg} ; \mathrm{p}$ 0.07). Moreover, the 'baseline' level of catecholamine use (norepinephrine, NA) was roughly similar (NA, K 0.45 vs E $0.2 \mathrm{mg} / \mathrm{h} ; \mathrm{p} \mathrm{0.11).}$

Post RSI, HR and MAP were similarly comparable between the two groups (HR, K 115 vs E $113 \mathrm{mmHg} ; \mathrm{p} \mathrm{0.80)}$ ) and mean arterial pressure (MAP, K 76 vs E $75 \mathrm{mmHg}$; $\mathrm{p} \mathrm{0.9)}$ ). The peak level of norepinephrine to maintain the MAP during sedation, though, was considerably higher in patients who received the etomidate regimen (NA, K 1.06 vs $\mathrm{E} 7.6 \mathrm{mg} / \mathrm{h} ; \mathrm{p} 0.01$. Detailed information is given in Table 2, Figure $\mathbf{1}$ and $\mathbf{2}$.

\section{USCOM measurements during RSI (CI, SVI, SVRI)}

USCOM measurements were performed immediately prior to $\mathrm{RSI}$, during RSI and post RSI (mean $\Delta$ between first and second

Table 1. Patient baseline characteristics (at ICU admission, prior to RSI)

\begin{tabular}{|c|c|c|c|}
\hline \multicolumn{4}{|l|}{ baseline characteristics $n=40$} \\
\hline median age (years) & 59 & 56 & range 31 - 91 \\
\hline gender ( $m / f)$ & $11 / 9$ & $12 / 8$ & \\
\hline \multirow[t]{2}{*}{ median SAPS II score } & 54 & 50 & range $24-81$ \\
\hline & $\begin{array}{l}\text { ketamine } \\
\text { group } \\
n=20\end{array}$ & $\begin{array}{l}\text { etomidate } \\
\text { group } \\
n=20\end{array}$ & $\mathrm{n}(\%)$ \\
\hline \multicolumn{4}{|l|}{ Underlying disease } \\
\hline liver cirrhosis \& GI bleeding & 6 & 5 & $11(27.5)$ \\
\hline acute leukaemia & 5 & 1 & $6(15.0)$ \\
\hline Iymphoma & 2 & 5 & $7(17.5)$ \\
\hline solid tumor & 3 & 3 & $6(15.0)$ \\
\hline other & 4 & 6 & $10(25.0)$ \\
\hline \multicolumn{4}{|l|}{$\begin{array}{l}\text { Need for intubation, } \\
\text { due to ... }\end{array}$} \\
\hline \multicolumn{4}{|l|}{ Respiratory failure } \\
\hline and/or Sepsis & 16 & 17 & $33(82.5)$ \\
\hline Sopor or coma * & 1 & - & $1(2.5)$ \\
\hline GI bleeding & 3 & 3 & $6(15.0)$ \\
\hline \multicolumn{4}{|l|}{ Outcome } \\
\hline Day 30 mortality rate & $60 \%(12 / 20)$ & $50 \%(10 / 20)$ & $22 / 40(55 \%)$ \\
\hline \multicolumn{4}{|l|}{ Mean time between USCOM } \\
\hline$\Delta(\min . \pm S D)$ & $5.7( \pm 2.34)$ & $6.3( \pm 2.85)$ & \\
\hline
\end{tabular}

Abbreviations: * ${ }^{*}$ opor or coma not related to sepsis (hepatic encephalopathy; GI, gastrointestinal; SD, standard deviation.
USCOM (minutes): 5.7 (K) vs 6.33 (E) (p 0.46). We recorded the following parameters: SVI, stroke volume index; $\mathrm{Cl}$, cardiac index; and SVRI, systemic vascular resistance index.

Prior to RSI, median $\mathrm{Cl}$ and SVI was comparable within both groups (mean SVI E $29.3 \mathrm{~mL} / \mathrm{m}^{2}$ vs SVI K $31.3 \mathrm{~mL} / \mathrm{m}^{2}$, p 0.55; mean CI E $2.9 \mathrm{~L} / \mathrm{min} / \mathrm{m}^{2}$ vs CI K $3.3 \mathrm{~L} / \mathrm{min} / \mathrm{m}^{2}$, p 0.23). The mean SVRI (dyn $\left.\times \mathrm{s} \times \mathrm{cm}^{-5} / \mathrm{m}^{2}\right)$ was higher in the etomidate group ( 2925(E) vs 2098 (K), p 0.04).

While mean $\mathrm{SVI} / \mathrm{Cl}\left(\mathrm{mL} / \mathrm{m}^{2} / \mathrm{L} / \mathrm{min} / \mathrm{m}^{2}\right)$ minimally increased during RSI (prior RSI 31.3/3.3, post RSI; 32.5/3.4, $\Delta+3.8 \% /+3.0 \%)$ within the ketamine group, mean SVI/CI (mL/ $\mathrm{m}^{2} / \mathrm{L} / \mathrm{min} / \mathrm{m}^{2}$ ) slightly decreased in the etomidate group (prior RSI 29.3/2.9, post RSI 26.8/2.8, $\Delta-8.5 \% /-3.5 \%$ ). Mean SVRI (dyn x s x cm${ }^{-5} / \mathrm{m}^{2}$ ) increased in the ketamine group and decreased in the etomidate group $(\Delta \mathrm{K}+10.2 \%, \Delta \mathrm{E}-3.8 \%)$. Detailed information is given in Table 2 .

Table 2. Hemodynamic parameters (by USCOM) prior to and after RSI

\begin{tabular}{|c|c|c|c|}
\hline & $\begin{array}{c}\text { ketamine } \\
n=20\end{array}$ & $\begin{array}{c}\text { etomidate } \\
n=20\end{array}$ & $\begin{array}{c}\mathrm{p} \\
\text { value } \\
*\end{array}$ \\
\hline \multicolumn{4}{|l|}{ Mean MAP (mmHg) } \\
\hline prior to RSI & $75 \pm 21.1$ & $88 \pm 22.3$ & 0.07 \\
\hline post RSI & $76 \pm 28.5$ & $75 \pm 31.7$ & 0.9 \\
\hline$\triangle$ MAP mmHg (\%) & $+1(+1.3)$ & $-3(-14.8)$ & \\
\hline \multicolumn{4}{|l|}{ Mean HR (bpm) } \\
\hline prior to RSI & $104 \pm 25.4$ & $107 \pm 28.3$ & 0.67 \\
\hline post RSI & $115 \pm 24.4$ & $113 \pm 29.8$ & 0.80 \\
\hline$\Delta \mathrm{HR}$ bpm (\%) & $+11(+10.6)$ & $+6(+5.6)$ & \\
\hline \multicolumn{4}{|l|}{ Mean $\mathrm{Cl}\left(\mathrm{L} / \mathrm{min} / \mathrm{m}^{2}\right)$} \\
\hline prior to RSI & $3.3 \pm 1.3$ & $2.9 \pm 0.9$ & 0.23 \\
\hline post RSI & $3.4 \pm 1.5$ & $2.8 \pm 1.1$ & 0.19 \\
\hline$\Delta \mathrm{Cl} \mathrm{L} / \mathrm{min} / \mathrm{m}^{2}(\%)$ & $+0.1(+3.0)$ & $-0.1(-3.5)$ & \\
\hline \multicolumn{4}{|l|}{ Mean SVI $\left(\mathrm{ml} / \mathrm{m}^{2}\right)$} \\
\hline prior to RSI & $31.3 \pm 10.2$ & $29.3 \pm 10.5$ & 0.55 \\
\hline post RSI & $32.5 \pm 13.3$ & $26.8 \pm 10.4$ & 0.15 \\
\hline$\Delta \mathrm{SVI} \mathrm{ml} / \mathrm{m}^{2}(\%)$ & $+1.2(+3.8)$ & $-2.5(-8.5)$ & \\
\hline \multicolumn{4}{|l|}{ Mean SVRI (dyn x s x cm-5/m²) } \\
\hline prior to RSI & $2098 \pm 805$ & $2925 \pm 1092$ & 0.04 \\
\hline post RSI & $2312 \pm 1118$ & $2813 \pm 1414$ & 0.32 \\
\hline$\Delta$ SVRI dyn x s x cm-5/m² (\%) & $+214(+10.2)$ & $-112(-3.8)$ & \\
\hline \multicolumn{4}{|l|}{ Mean NA (maximum)* } \\
\hline prior to RSI (mg/h iv) & $0.45 \pm 0.6$ & $0.2 \pm 0.3$ & 0.11 \\
\hline post RSI (mg/h iv) & $1.06 \pm 0.7$ & $7.6 \pm 10.2$ & 0.01 \\
\hline$\triangle N A(\%)$ & $+0.61(+136)$ & $+7.4(+3.400)$ & \\
\hline
\end{tabular}

Abbreviations: MAP, mean arterial pressure; RSI, rapid sequence induction; ${ }^{*}$ t-test; NA, norepinephrine; HR, heart rate; CI, cardiac index; SVI, stroke volume index; SVRI, systemic vascular resistance index; SVI, stroke volume index; SVV, stroke volume variance; \pm SD, standard deviation

* Norepinephrine $0.1 \mathrm{mg} / \mathrm{h}=1.67 \mu \mathrm{g} / \mathrm{min}$. (averaged $70 \mathrm{~kg}=0.023 \mu \mathrm{g} / \mathrm{kg} / \mathrm{min}$ ) 
Figure 1. MAP prior to - and post RSI (mean \pm standard deviation)

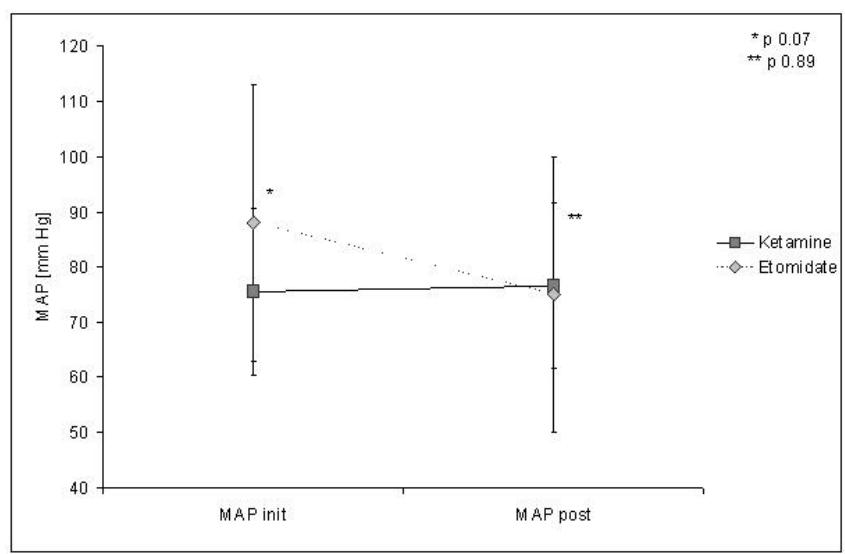

Figure 2. Peak level of norepinephrine prior to - and post RSI

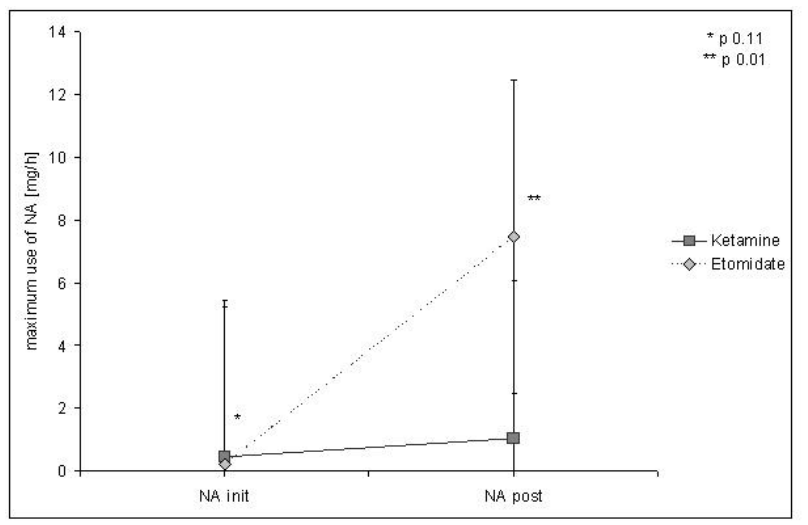

\section{Outcomes}

Twelve of 20 patients within the ketamine group have died within 30 days (day 30 mortality rate $60 \%$ ), and 10 of 20 patients have died in the etomidate group (day 30 mortality rate $50 \%$ ). Overall day 30 mortality was $55 \%$.

\section{Discussion}

Although adrenal axis dysfunction arises to some extent after etomidate use for RSI, the effect of such adrenal suppression on patients' outcome remains debated. Several studies have reported increased mortality in patients who had received one bolus of etomidate $[\mathbf{4 , 5}, \mathbf{2 3}]$. However, these findings have not

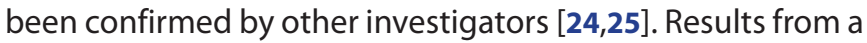
recent randomized trial indicated, that ketamine compared to the use of etomidate was comparable with regard to 28-day mortality [7]. The percentage of patients with adrenal insufficiency was significantly higher in regards to the etomidate group than in the ketamine group, but mortality did not differ significantly. Adrenal insufficiency is probably associated with increased mortality in critically ill patients, including those with sepsis; however, whether the adrenal axis suppression and mortality are the result of some underlying process, or whether it causes death, has never been established [7].

Jabre et al., concluded that ketamine is a safe and valuable alternative to etomidate for RSI in critically ill patients, particularly in septic patients, even though the study might not have had sufficient power to show a significant increase in morbidity related to the use of etomidate in patients with sepsis.

This pilot study aimed to evaluate the influence of a ketamine-based vs an etomidate-based anesthetization on hemodynamic parameters measured by USCOM immediately prior to, during and post RSI. Intubation was indicated mainly for respiratory failure and/or sepsis.

Clearly, the still accepted clinical standard for CO measurement is the intermittent thermodilution technique which itself has its own inherent variability [26-28]. USCOM is a noninvasive cardiac output monitor based on the transthoracic measurement of Doppler flow velocity over the aortic and pulmonary outflow tract. It is easy to operate, and $\mathrm{CO}$ is displayed 'beat by beat'. Following a short booting time the device can be used immediately. The technique is reported to be easily learned after a short period by non-physicians $[29,30]$. Previously reported trials investigated the accuracy of USCOM in various settings and most of them found an acceptable agreement between the USCOM CO measurements and those determined by a thermodilution-based method $[15,29,22,31-34,16,35,20]$. Although, it is critical to report, that an inferior accuracy for USCOM was reported by other authors who found that CO measurements by USCOM do not reliably represent absolute values as compared to pulmonary artery catheter thermodilution technique $[36,35]$.

Prior to RSI, patients were roughly comparable regarding baseline hemodynamic parameters (HR, MAP, Cl, and SVI) and norepinephrine use. But the peak level of norepinephrine to maintain MAP during induction, though, was considerably higher in patients who received etomidate/fentanyl for sedation (NA, K 1.06 vs E 7.6 mg/h; p 0.01). Post RSI USCOM measurements showed slightly increased means of SVI/CI $\left(\mathrm{mL} / \mathrm{m}^{2}, \mathrm{~L} / \mathrm{min} / \mathrm{m}^{2} ; \Delta+3.8 \%,+3.0 \%\right)$ within the ketamine group, whereas those in the etomidate group decreased (prior RSI 29.3/2.9, post RSI 26.8/2.8; $\Delta-8.5 \% /-3.5 \%)$. The mean SVRI (dyn $\times \mathrm{s} \times \mathrm{cm}^{-5} / \mathrm{m}^{2}$ ) increased in the ketamine group and decreased in the etomidate group $(\Delta \mathrm{K}+10.2 \%, \Delta \mathrm{E}-3.8 \%)$.

The present data confirm the conclusion of Jabre et al. regarding safety and valuability of ketamine use for RSI. Moreover, USCOM measurements during RSI support the excellent hemodynamic tolerance of ketamine in the present patients setting. Considering the contraindications, ketamine advanced to our $1^{\text {st }}$ choice sedative in septic patients requiring intubation.

However, drawing final conclusions from the present study is almost impossible. The patients' number is considerably low. Moreover, patients were alternately, but not randomly assigned to receive either etomidate or ketamine. Moreo- 
ver, there is a limitation since the patients have received a combination (etomidate/fentanyl vs ketamine/midazolam) for RSI. We cannot exclude that differences in hemodynamic changes during RSI can be attributed to the drug combination given. Furthermore, USCOM itself is associated with some restrictions. Patients in our study for instance, were ventilated mechanically post-RSI which contributes to difficulties in $\mathrm{CO}$ measurements by an ultrasound-based device. Moreover, some studies indicated that USCOM tends to underestimate the real CO value when it is relatively high [16-18]. On the contrary, such a difference does not appear in Su et al's research $[17,18]$. They investigated patients with liver cirrhosis because of their unique hyperdynamic status with high $\mathrm{CO}$ values ranged up to $13.6 \mathrm{~L} / \mathrm{min}$, and found that even at high CO values, USCOM still reliably measures CO $[17,18]$.

\section{Conclusion}

We agree with Jabre et al., that ketamine is a safe and valuable alternative to etomidate for RSI. Particularly, in septic patients, with primary necessity for vasopressants, USCOM measurements during RSI support the excellent hemodynamic tolerance of ketamine in such a patients setting. For hemodynamic monitoring, USCOM is easy to use, and the physician will obtain a result in an unbeatable period of time. It seems to be appropriate in situations where CO measurement is most pertinent to patient management.

\section{Competing interests}

The Author's declare that they have no competing interests.

\section{Authors contributions}

Geiger S, Stemmler HJ, Strecker N, Horster

$\mathrm{S}$ - study design, patient recruitment, USCOM ex-

aminations, preparation of manuscript

Tischer J, Pastore A, Hausmann A - data man-

agement, preparation of manuscript.

\section{Publication history}

Received: 10-May-2012 Revised: 10-July-2012

Accepted: 12-July-2012 Published: 02-Aug-2012

\section{References}

1. Malerba G, Romano-Girard F, Cravoisy A, Dousset B, Nace L, Levy $B$, et al.: Risk factors of relative adrenocortical deficiency in intensive care patients needing mechanical ventilation. Intensive Care Med 2005; 31;(3.);388-92. | Article I PubMed

2. de Jong FH, Mallios $C$, Jansen $C$, Scheck PA, Lamberts SW: Etomidate suppresses adrenocortical function by inhibition of 11 beta-hydroxylation. J Clin Endocrinol Metab 1984; 59;(6.);1143-7. I Article I PubMed

3. de Jong MF, Beishuizen A, Spijkstra JJ, Groeneveld AB: Relative adrenal insufficiency as a predictor of disease severity, mortality, and beneficial effects of corticosteroid treatment in septic shock. Crit Care Med 2007; 35;(8.);1896-903. | Article | PubMed

4. Lipiner-Friedman $D$, Sprung $C L$, Laterre PF, Weiss $Y$, Goodman SV, Vogeser M, et al.: Adrenal function in sepsis: the retrospec- tive Corticus cohort study. Crit Care Med 2007; 35;(4.);1012-8. | Article | PubMed

5. den Brinker M, Hokken-Koelega AC, Hazelzet JA, de Jong FH, Hop WC, Joosten KF: One single dose of etomidate negatively influences adrenocortical performance for at least $24 \mathrm{~h}$ in children with meningococcal sepsis. Intensive Care Med 2008; 34;(1.);163-8. | Article | PubMed Abstract | PubMed Full Text

6. Hildreth AN, Mejia VA, Maxwell RA, Smith PW, Dart BW, Barker $D E$ : Adrenal suppression following a single dose of etomidate for rapid sequence induction: a prospective randomized study. J Trauma 2008; 65;(3.);573-9. I Article I PubMed

7. Jabre $P$, Combes $X$, Lapostolle F, Dhaouadi M, Ricard-Hibon A, Vivien $B$, et al.: Etomidate versus ketamine for rapid sequence intubation in acutely ill patients: a multicentre randomised controlled trial. Lancet 2009; 374;(9686.);293-300. | Article | PubMed

8. Swan HJ, Ganz W: Measurement of right atrial and pulmonary arterial pressures and cardiac output: clinical application of hemodynamic monitoring. Adv Intern Med 1982; 27;(453-73. | Article I PubMed

9. Ganz W, Donoso R, Marcus HS, Forrester JS, Swan HJ: A new technique for measurement of cardiac output by thermodilution in man. Am J Cardiol 1971; 27;(4.);392-6. | Article | PubMed

10. Rocco M, Spadetta G, Morelli A, Dell'Utri D, Porzi P, Conti G, et al.: A comparative evaluation of thermodilution and partial CO2 rebreathing techniques for cardiac output assessment in critically ill patients during assisted ventilation. Intensive Care Med 2004; 30;(1.);82-7. | Article | PubMed

11. Boldt J: Clinical review: hemodynamic monitoring in the intensive care unit. Crit Care 2002; 6;(1.);52-9. | Article | PubMed Abstract | PubMed Full Text

12. Cooper AB, Doig GS, Sibbald WJ: PULMONARY ARTERY CATHETERS IN THE CRITICALLY ILL: An Overview Using the Methodology of Evidence-Based Medicine. Critical Care Clinics 1996; 12;(4.);777-94. I Article

13. Sakka SG, Reinhard K, Wegscheider K, Meier-Hellmann A: Is the placement of a pulmonary artery catheter still justified solely for the measurement of cardiac output? Journal of Cardiothoracic and Vascular Anesthesia 2000; 14;(2.);119-24. | Article

14. Antonini M, Meloncelli S, Dantimi C, Tosti S, Ciotti L, Gasparetto A: [The PiCCO system with brachial-axillary artery access in hemodynamic monitoring during surgery of abdominal aortic aneurysm]. Minerva Anestesiol 2001; 67;(6.);447-56. | PubMed

15. Critchley LA, Peng ZY, Fok BS, Lee A, Phillips RA: Testing the Reliability of a New Ultrasonic Cardiac Output Monitor, the USCOM, by Using Aortic Flowprobes in Anesthetized Dogs. Anesthesia \& Analgesia 2005; 100;(3.);748-53. | Article

16. Tan HL, Pinder M, Parsons R, Roberts B, van Heerden PV: Clinical evaluation of USCOM ultrasonic cardiac output monitor in cardiac surgical patients in intensive care unit. Br J Anaesth 2005; 94;(3.);287-91. | Article | PubMed

17. Su BC, Lin CC, Su CW, Hui YL, Tsai YF, Yang MW, et al.: Ultrasonic cardiac output monitor provides accurate measurement of cardiac output in recipients after liver transplantation. Acta Anaesthesiol Taiwan 2008; 46;(4.);171-7. I Article I PubMed

18. Su BC, Yu HP, Yang MW, Lin CC, Kao MC, Chang CH, et al.: Reliability of a new ultrasonic cardiac output monitor in recipients of living donor liver transplantation. Liver Transp/ 2008; 
14;(7.);1029-37. I Article I PubMed

19. Knobloch K, Lichtenberg A, Winterhalter M, Rossner D, Pichlmaier M, Phillips R: Non-invasive cardiac output determination by two-dimensional independent Doppler during and after cardiac surgery. Ann Thorac Surg 2005; 80;(4.);1479-83. I Article I PubMed

20. van Lelyveld-Haas LE, van Zanten AR, Borm GF, Tjan DH: Clinical validation of the non-invasive cardiac output monitor USCOM-1A in critically ill patients. Eur J Anaesthesiol 2008; 25;(11.);917-24. | Article | PubMed

21. Rivers E, Nguyen B, Havstad S, Ressler J, Muzzin A, Knoblich B, et al.: Early goal-directed therapy in the treatment of severe sepsis and septic shock. N Engl J Med 2001; 345;(19.);1368-77. | Article | PubMed

22. Horster S, Stemmler HJ, Strecker N, Brettner F, Hausmann A, Cnossen J, et al.: Cardiac Output Measurements in Septic Patients: Comparing the Accuracy of USCOM to PiCCO. Crit Care Res Pract 2012; 2012;(270631. | Article | PubMed Abstract | PubMed Full Text

23. Sprung CL, Annane D, Keh D, Moreno R, Singer M, Freivogel K, et al.: Hydrocortisone therapy for patients with septic shock. $N$ Engl J Med 2008; 358;(2.);111-24. | Article | PubMed

24. Riche FC, Boutron CM, Valleur P, Berton C, Laisne MJ, Launay $\mathrm{JM}$, et al.: Adrenal response in patients with septic shock of abdominal origin: relationship to survival. Intensive Care Med 2007; 33;(10.);1761-6. | Article | PubMed

25. Ray DC, McKeown DW: Effect of induction agent on vasopressor and steroid use, and outcome in patients with septic shock. Crit Care 2007; 11;(3.);R56. | Article | PubMed Abstract | PubMed Full Text

26. Jansen JR: The thermodilution method for the clinical assessment of cardiac output. Intensive Care Med 1995; 21;(8.);6917. | Article | PubMed

27. Thrush DN, Varlotta D: Thermodilution cardiac output: Comparison between automated and manual injection of indicator. Journal of Cardiothoracic and Vascular Anesthesia 1992; 6;(1.);17-9. I Article

28. Botero M, Kirby D, Lobato EB, Staples ED, Gravenstein N: Measurement of cardiac output before and after cardiopulmonary bypass: Comparison among aortic transit-time ultrasound, thermodilution, and noninvasive partial $\mathrm{CO} 2$ rebreathing. Journal of Cardiothoracic and Vascular Anesthesia 2004; 18;(5.);563-72. I Article

29. Dey I, Sprivulis P: Emergency physicians can reliably assess emergency department patient cardiac output using the USCOM continuous wave Doppler cardiac output monitor. Emergency Medicine Australasia 2005; 17;(3.);193-9. | Article

30. Knobloch K, Hubrich V, Rohmann P, Lupkemann M, Gerich T, Krettek C, et al.: Feasibility of preclinical cardiac output and systemic vascular resistance in HEMS in thoracic pain--the ultrasonic cardiac output monitor. Air Med J 2006; 25;(6.);2705. | Article | PubMed

31. Knobloch K: Non-invasive hemodynamic monitoring using USCOM in HEMS at the scene. J Trauma 2007; 62;(4.);1069-70; author reply 70. | Article | PubMed

32. Knobloch K, Tepe J, Rossner D, Lichtinghagen R, Luck HJ, Busch $\mathrm{KH}$, et al.: Combined NT-pro-BNP and CW-Doppler ultrasound cardiac output monitoring (USCOM) in epirubicin and liposomal doxorubicin therapy. Int J Cardiol 2008; 128;(3.);316-25. I
Article | PubMed

33. Siu CW, Tse HF, Lee K, Chan HW, Chen WH, Yung C, et al.: Cardiac resynchronization therapy optimization by ultrasonic cardiac output monitoring (USCOM) device. Pacing Clin Electrophysiol 2007; 30;(1.);50-5. I Article I PubMed

34. Stemmler HJ, Weigert O, Grüner N, Tschöp K, Lange V, et al.: Non-invasive hemodynamic monitoring in critically ill patients: Experience with the USCOM device. Intensivmed 2007; 44 (44):366-71.

35. Van den Oever HL, Murphy EJ, Christie-Taylor GA: USCOM (Ultrasonic Cardiac Output Monitors) lacks agreement with thermodilution cardiac output and transoesophageal echocardiography valve measurements. Anaesth Intensive Care 2007; 35;(6.);903-10. I Article I PubMed

36. Knirsch W, Kretschmar O, Tomaske M, Stutz K, Nagdyman N, Balmer $\mathrm{C}$, et al.: Cardiac output measurement in children: comparison of the Ultrasound Cardiac Output Monitor with thermodilution cardiac output measurement. Intensive Care Med 2008; 34;(6.);1060-4. | Article | PubMed

\section{Citation:}

Geiger S, Stemmler H J, Strecker N, Tischer J, Pastore A, Hausmann A and Horster S: Hemodynamic monitoring by USCOM during rapid sequence intubation (RSI) with Etomidate/Fentanyl or Ketamine/Midazolam. journal of Anesthesiology and Clinical Science 2012, 1:7. http://dx.doi.org/10.7243/2049-9752-1-7 